\title{
RESEARCH
}

Open Access

\section{Cost-effectiveness of physical activity intervention in children - results based on the Physical Activity and Nutrition in Children (PANIC) study}

Virpi Kuvaja-Köllner ${ }^{1 *}$, Niina Lintu², Virpi Lindi ${ }^{2,3^{\wedge}}$, Elisa Rissanen ${ }^{1}$, Aino-Maija Eloranta ${ }^{2,4}$, Sanna Kiiskinen ${ }^{2}$, Janne Martikainen ${ }^{5}$, Eila Kankaanpää ${ }^{1}$, Hannu Valtonen ${ }^{1}$ and Timo A. Lakka ${ }^{2,6,7}$

\begin{abstract}
Background: We assessed the cost-effectiveness of a 2-year physical activity (PA) intervention combining familybased PA counselling and after-school exercise clubs in primary-school children compared to no intervention from an extended service payer's perspective.

Methods: The participants included 506 children (245 girls, 261 boys) allocated to an intervention group (306 children, $60 \%$ ) and a control group (200 children, $40 \%$ ). The children and their parents in the intervention group had six PA counselling visits, and the children also had the opportunity to participate in after-school exercise clubs. The control group received verbal and written advice on health-improving PA at baseline. A change in total PA over two years was used as the outcome measure. Intervention costs included those related to the family-based PA counselling, the after-school exercise clubs, and the parents' taking time off to travel to and participate in the counselling. The cost-effectiveness analyses were performed using the intention-to-treat principle. The costs per increased PA hour (incremental cost-effectiveness ratio, ICER) were based on net monetary benefit (NMB) regression adjusted for baseline PA and background variables. The results are presented with NMB and cost-effectiveness acceptability curves.

Results: Over two years, total PA increased on average by $108 \mathrm{~h}$ in the intervention group ( $95 \%$ confidence interval [CI] from 95 to $121, p<0.001)$ and decreased by $65.5 \mathrm{~h}(95 \% \mathrm{Cl}$ from 81.7 to $48.3, p<0.001)$ in the control group, the difference being $173.7 \mathrm{~h}$. the incremental effectiveness was 87 (173/2) hours. For two years, the intervention costs were $€ 619$ without parents' time use costs and $€ 860$ with these costs. The costs per increased PA hour were $€ 6.21$ without and $€ 8.62$ with these costs. The willingness to pay required for $95 \%$ probability of costeffectiveness was $€ 14$ and $€ 19$ with these costs. The sensitivity analyses revealed that the ICER without assuming this linear change in PA were $€ 3.10$ and $€ 4.31$.
\end{abstract}

Conclusions: The PA intervention would be cost-effective compared to no intervention among children if the service payer's willingness-to-pay for a 1-hour increase in PA is $€ 8.62$ with parents' time costs.

\footnotetext{
* Correspondence: virpi-liisa.kuvaja-kollner@uef.fi

${ }^{1}$ Department of Health and Social Management, University of Eastern Finland, Kuopio, Finland

Full list of author information is available at the end of the article
}

(C) The Author(s). 2021 Open Access This article is licensed under a Creative Commons Attribution 4.0 International License, which permits use, sharing, adaptation, distribution and reproduction in any medium or format, as long as you give appropriate credit to the original author(s) and the source, provide a link to the Creative Commons licence, and indicate if changes were made. The images or other third party material in this article are included in the article's Creative Commons licence, unless indicated otherwise in a credit line to the material. If material is not included in the article's Creative Commons licence and your intended use is not permitted by statutory regulation or exceeds the permitted use, you will need to obtain permission directly from the copyright holder. To view a copy of this licence, visit http://creativecommons.org/licenses/by/4.0/. The Creative Commons Public Domain Dedication waiver (http://creativecommons.org/publicdomain/zero/1.0/) applies to the data made available in this article, unless otherwise stated in a credit line to the data. 
Trial registration: ClinicalTrials.gov: NCT01803776. Registered 4 March 2013 - Retrospectively registered, https:// clinicaltrials.gov/ct2/results?cond=\&term $=01803776 \&$ cntry $=\&$ state $=\&$ city $=\&$ dist $=$.

Keywords: Physical activity, Children, Cost-effectiveness, Intervention, Multicomponent, Family, School, Net monetary benefit

\section{Introduction}

Low levels of physical activity (PA) have been associated with increased risk of various chronic diseases and therefore with increased health care costs $[1,2]$. PA habits are often formed early in life [3-6], and lifestylerelated chronic diseases, such as type 2 diabetes, start to develop already during the fetal period [7]. According to a recent review on PA interventions carried out in childhood, parents play a key role in promoting their children's PA [8]. Multicomponent interventions, such as school-based interventions in combination with involvement of families or communities, have also been found to be effective in increasing PA among adolescents [810].

Healthcare decision makers increasingly require scientific evidence to support their decisions on the allocation of available resources [11]. Economic evaluation comparing the costs and effectiveness of different interventions helps in identifying the best option for the efficient use of healthcare resources [12]. The key question in economic evaluation is whether the intervention represents "value for money" [13]. Although there have been a large number of studies to investigate the effectiveness of PA interventions in increasing PA and thereby improving health in children, only a few of them have included economic evaluation [14-19]. Moreover, many studies reporting the cost-effectiveness of lifestyle interventions have been carried out only among overweight children $[18,19]$. Another option to evaluate the economic consequences of interventions would be to use a modelling study based on the results of an effectiveness study [2022].

There is some evidence for the cost-effectiveness of school-based PA interventions [23], particularly when no extra-staff was required to carry out the interventions [17]. However, little is known about the costeffectiveness of family-based PA interventions. We therefore assessed the cost-effectiveness of a 2-year family-based PA intervention from the perspective of a municipality as a service payer and additionally extended the analyses by including parents' time use costs in a general population of primary-school children.

\section{Methods}

\section{Study design and study population}

The Physical Activity and Nutrition in Children (PANIC) study is a controlled trial on the effects of a combined PA and dietary intervention on cardiometabolic risk factors and other health outcomes in a population sample of children from the city of Kuopio, Finland [24, 25]. The Research Ethics Committee of the Hospital District of Northern Savo approved the study protocol in 2006 (Statement 69/2006). The parents or caregivers of the children gave their written informed consent, and the children provided their assent to participation. The PANIC study has been carried out in accordance with the principles of the Declaration of Helsinki as revised in 2008.

We invited 736 children aged 6-9 years who started the first grade in 16 primary schools of the city of Kuopio in 2007-2009 to participate in the study (Additional file 1). Altogether, 512 (70\%) children (248 girls, 264 boys) accepted the invitation and participated in the baseline examinations between October 2007 and December 2009. The participants did not differ in sex, age, height - standard deviation score (SDS) or body mass index (BMI) - SDS from all children who started the first grade in the city of Kuopio in 2007-2009. We excluded six children from the study at baseline either because of physical disabilities that could hamper participation in the intervention or who had no time or motivation to attend the study. The final study sample thus included 506 children at baseline.

We allocated the children from nine schools to a combined PA and dietary intervention group (306 children, $60 \%$ ) and the children from seven schools to a control group (200 children, $40 \%$ ) to avoid contamination in the control group by after-school exercise clubs organised in the nine schools or any local or national health promotion programmes that could have been initiated in the study region during the follow-up period. We also proportionally matched the intervention and control group according to the location of the schools (urban vs. rural) to minimise sociodemographic differences between the groups. We included more children in the intervention group than in the control group because of a larger number of dropouts expected in the intervention group and to retain a sufficient statistical power for comparison between the groups. A total of 261 children ( $85 \%$ of those invited) from the intervention group and 179 $(90 \%)$ children from the control group participated in the 2-year follow-up examinations between November 2009 and January 2012. The median (interquartile range) of follow-up time was $2.1(2.1-2.2)$ years in the 
intervention and control group. Data on PA used in the analyses were available for 503 children (244 girls, 259 boys) at baseline and for 431 children (210 girls, 221 boys) at 2-year follow-up. (Flow chart Additional file 1)

\section{Physical activity intervention}

The 2-year PA intervention included six family-based and tailored PA counselling visits organised during office hours for each family [26]. The children and their parents received individual advice from an exercise medicine specialist on how to increase PA and decrease sedentary time of the children in everyday conditions. Each visit had a specific topic of discussion in accordance with the goals of the intervention and included practical tasks on these topics for the children. The families also received fact sheets on PA and sedentary time as well as verbal and written information on opportunities for exercising in the city of Kuopio. Minor gifts, such as exercise equipment and admission to indoor sports facilities, were given for all families to support PA of the children. The timing and topics of and the time of exercise medicine specialists used for the family-based and tailored PA counselling visits are presented in Table 1. Of the 306 children in the intervention group who attended the baseline examination, 266 (87\%) participated in all six visits, 281 (92\%) in at least five visits, and $295(96 \%)$ in at least four visits.

The children in the intervention group, particularly those who did not attend organised sports or exercise, were also encouraged to participate in after-school exercise clubs organised at the nine schools by trained exercise instructors of the PANIC study. There were a total of 24 after-school exercise clubs that lasted $60 \mathrm{~min}$ and took place on average once a week. Altogether, 254 $(87 \%)$ of the 306 children in the intervention group participated in at least one of the after-school exercise club sessions, and 124 (41\%) of these children attended the exercise clubs at least once a month. The children participated in on average 23 (95\% confidence interval 20-26) of all 76 exercise club sessions.

In the control group, the children and their parents received general verbal and written advice on healthimproving PA at baseline but no further PA counselling. The children in the control group normally participated in the compulsory $1.5 \mathrm{~h}$ of physical education per week, but they were not allowed to attend the after-school exercise clubs to avoid a non-intentional intervention in the control group.

\section{Assessment of physical activity}

Total time used for PA during a usual week was assessed using the PANIC Physical Activity Questionnaire, filled out by the parents or caregivers at baseline and at 2-year follow-up [27]. This questionnaire has been validated in a subsample of children from the PANIC Study by the Actiheart ${ }^{\circledR}$ monitor [28]. The types of PA in the questionnaire included unsupervised PA, organised sports, organised exercise other than sports, physically active school transportation, and PA during recess. Total weekly PA was calculated by summing the time spent for different types of PA. The compulsory $1.5 \mathrm{~h}$ of physical education per week for all children aged 7-15 years in Finnish schools was included in total PA.

\section{Assessment of socioeconomic background}

Socioeconomic status, including parental education and household income, was reported by the parents or caregivers at baseline. The degree of the more educated parent was used as parental education in the analysis [29]. Household income was divided into three categories $(\leq$ $30,000 € /$ year, $30,001-60,000 € /$ year, and $\geq 60,001$ $€ /$ year).

\section{Resources used and related costs}

The costs of the PA intervention included those related to the family-based PA counselling visits, the after-

Table 1 Timing and topics of the family-based and tailored physical activity counselling visits

\begin{tabular}{|c|c|c|}
\hline Timing of the visits & Main topics of the visits & $\begin{array}{l}\text { Time used for the } \\
\text { visits }\end{array}$ \\
\hline $\begin{array}{l}0.5 \text { months after } \\
\text { baseline }\end{array}$ & $\begin{array}{l}\text { Introducing the families to the content of the intervention and an overview of a physically active } \\
\text { lifestyle }\end{array}$ & $15 \mathrm{~min}$ \\
\hline $\begin{array}{l}1.5 \text { months after } \\
\text { baseline }\end{array}$ & Supporting spontaneous physical activity in children & $70 \min$ \\
\hline 3 months after baseline & $\begin{array}{l}\text { Supporting the aim of achieving recommended amount of physical activity, sedentary time, and } \\
\text { sleep }\end{array}$ & $30 \min$ \\
\hline 6 months after baseline & Increasing physical activity in everyday life and with the family & $35 \mathrm{~min}$ \\
\hline $\begin{array}{l}12 \text { months after } \\
\text { baseline }\end{array}$ & Supporting the development of motor skills & $40 \min$ \\
\hline $\begin{array}{l}18 \text { months after } \\
\text { baseline }\end{array}$ & Health benefits of a physically active lifestyle & $30 \min$ \\
\hline Total time used & & $220 \mathrm{~min}$ \\
\hline
\end{tabular}


school exercise club sessions, and the parents' or the caregivers' taking time off for traveling to and participating in the counselling, but not those related to planning the PA intervention. In the cost-effectiveness analyses, the costs of the PA intervention were assumed to be similar for all participants in the intervention group, and those for the control group were assumed to be zero.

The costs of the family-based PA counselling visits included the salary of the exercise medicine specialist; the printed material for the parents or the caregivers; minor gifts, such as exercise equipment and admission to indoor sports facilities, to support PA of the children; and healthy snacks served to the children during the PA counselling visits. The salary costs for the exercise medicine specialists are based on the time used for PA counselling and the average earnings for a person with a Master's degree in health sciences working in the municipal sector in Finland in 2011 of $3405 € /$ month [30] added by all social security costs of $40 \%$ [31].

Since the family-based PA counselling visits were organised during office hours, we assumed that one parent or caregiver needed to take time off to pick up the child from school and attend the visits. The estimated working time lost was valued according to the opportunity cost approach $[12,32]$. We estimated that each parent spent altogether $8.67 \mathrm{~h}$ for the PA counselling, calculated as $2.67 \mathrm{~h}(220 \mathrm{~min})$ for the six counselling visits + six hours for transportation to the six counselling visits (one hour for each visit). The costs of time used for the parents were valued using the average Finnish employee's earnings of $19.84 € /$ hour added by all social security costs of $40 \%$ in Finland in 2014 [31, 33].

The after-school exercise club sessions lasted $60 \mathrm{~min}$, and the trained exercise instructors used another $30 \mathrm{~min}$ for planning the sessions and transferring equipment. The salary costs of the exercise instructors were valued using the earnings of these employee in the city of Kuopio of $2246 € /$ month added by all social security costs of $40 \%$ in Finland in 2014 [31]. A school year in Finland includes 38 school weeks, so there were approximately 76 after-school exercise club sessions over two years in the 24 exercise clubs. For the analyses, the costs of the 76 exercise club sessions were multiplied by the number of the after-school exercise clubs of 24 , and the value was divided by the number of children in the intervention group of 306. The city of Kuopio provided the information used for the rental costs of school sports halls. There was large variation in the rental costs, and therefore their average was used in the analyses.

\section{Statistical methods}

All statistical analyses were performed using Stata 15 [34]. Differences in baseline characteristics, including gender, age, education, and income, between the intervention group and the control group as well as between children who completed the intervention and those who did not were analysed using the t-test for independent samples for normally distributed continuous variables and the Chi-squared test for categorical variables. The cost-effectiveness analyses were performed following the intention-to-treat principle [35]. Chained equation was used to impute missing values for PA [36, 37]. In these data, we assumed that the values were missing at random. Predictive mean matching with the five closest cases was used in the imputation model [38]. Gender, age, school, parental education, and household income at baseline were used as predictors to impute missing PA values at baseline and at 2-year follow-up. We had complete data on PA and background variables at baseline and at follow-up for $83 \%$ of the children and thus partly incomplete information for $17 \%$ of the children. The number of imputed datasets has been recommended to be similar to the percentage of study participants with partly incomplete information [39]. Therefore, 17 new datasets were imputed. The results of all imputed datasets were combined with other data using the Rubin's rules [38].

\section{Economic evaluation}

For the economic evaluation, the weekly hours of PA at baseline and at 2-year follow-up were spread over the 2year period to be comparable with the costs of the PA intervention over two years. Because it was not obvious when the change in PA took place during the two years, we assumed that it occurred linearly and used the trapezoidal rule $[40,41]$ and divided the area under the curve (area between baseline and 2-years measurement) by two, as shown in the following calculation formula. The change in PA over two years was calculated as (104 weeks * PA hours per week at 2-year follow-up)/2 (104 weeks * PA hours per week at baseline)/2.

The economic evaluation was performed using the net monetary benefit analysis with two main steps. Firstly, we calculated the net monetary benefit for each child in the dataset using the formula the net monetary benefit = $\lambda * E_{i}-C_{i}$, where $\lambda$ represents the threshold for willingness to pay for the specified outcome, $E_{i}$ is the observed effect for the subject, and $C_{i}$ is the costs for the subject $i$ [42]. Secondly, we performed regression analysis using each child's net monetary benefit as the dependent variable. The regression coefficient $\delta$ ti for the treatment dummy variable $(1=$ intervention, $0=$ control $)$ provides the estimate of the incremental net monetary benefit. When $\delta$ ti is higher than 0 , the incremental net monetary benefit is positive, and the intervention is cost-effective compared with control [42-44]. Other variables in the regression model were the intercept $\alpha$ and the stochastic error $\varepsilon_{\mathrm{i}}[45,46]$. PA, gender, age, parental education, 
and household income at baseline were added as independent variables and school at baseline was added as a cluster variable into the net benefit regression model $[45,46]$.

Net monetary benefit $=\llbracket \alpha+\delta \mathrm{t} \rrbracket \_\mathrm{i}+$ baseline $\mathrm{PA}+$ baseline age + gender + baseline parental education + baseline household income $+\varepsilon_{\mathrm{i}}$ \{school as cluster variable\}.

Cost-effectiveness acceptability curves were used to characterize uncertainty in the net monetary benefit according to willingness to pay for 1-hour increase in PA $[12,42,46,47]$. The results are also presented as incremental cost-effectiveness ratios, denoting the extra costs per an extra unit of effect, which can be found from the point where the incremental net monetary benefit turns positive [45].

\section{Sensitivity analysis}

To assess the robustness of the results, five sensitivity analyses were conducted. First, we tested whether the results would change if the costs were $20 \%$ higher. Second, as the most pessimistic option, we combined $20 \%$ lower effectiveness with $20 \%$ higher costs of the intervention. Third, we discounted the costs and the effectiveness by $3 \%$ [48]. Fourth, we included only children with complete data in the analyses. Fifth, as the most optimistic option, we assumed an immediate change in PA after the start of the follow-up. These sensitivity analyses were performed using the net monetary benefit regression, and the results are presented as threshold values with a probability of $50 \%$ of cost-effectiveness. All sensitivity analyses were performed by considering parents' time used and without it.

\section{Results}

\section{Characteristics of children}

The self-reported household income at baseline was statistically significantly higher in the intervention group than in the control group (Table 2). There were no differences in total PA or other baseline variables between the groups. There were more children in the lowest third of parental education and household income among non-completers than among completers in both groups $(\mathrm{p}<0.001)$.

The values are means (standard deviations) from the $\mathrm{T}$-test for independent samples for age and numbers (percentages) from the Chi-squared test for parental education and household income.

\section{Cost-effectiveness}

PA increased on average by 63 min per week (standard deviation [SD] 281, $95 \%$ confidence interval [CI] 55 to $70, p<0.001)$ in the intervention group and decreased by $38 \mathrm{~min}$ per week (SD 294, $95 \%$ CI 47 to $28, p<$ 0.001 ) in the control group over two years. Families in the highest third of household income were more likely to participate in all six PA counselling visits than families in the lowest third $(p=0.015)$.

PA increased on average by $108.2 \mathrm{~h}$ per child over two years in the intervention group and decreased average by $65.5 \mathrm{~h}$ per child over two years in the control group by using imputed and adjusted PA values in the economic evaluation (Table 3). Thus, the incremental effectiveness of the PA intervention was $173.7 \mathrm{~h}(108.2 \mathrm{~h}-(-65.5)$ hours) over two years $(p<0.001)$, and the linear effectiveness of the PA (173.7/2) intervention was $86.9 \mathrm{~h}$ over two years $(p<0.001)$.

The costs of the PA intervention, reflecting the resources used, were $619 €$ per child over two years without parents' time use costs (Table 4) and $860 €$ per child with parents' time use costs. Most of the costs were related to organizing after-school exercise clubs, such as personnel costs and rentals. Moreover, costs related to parents' time used played a major role. Other costs, such as those related to family-based PA counselling, were minor.

The PA intervention resulted in an incremental benefit of $87 \mathrm{~h}$ in PA and incremental program costs of $€ 619$

Table 2 Background characteristics of children at baseline

\begin{tabular}{llll}
\hline & Intervention group $(\boldsymbol{n = 3 0 6 )}$ & Control group $(\boldsymbol{n}=\mathbf{2 0 0})$ & $\boldsymbol{P}$-value \\
\hline Boys, $\mathrm{n}(\%)$ & $162(53)$ & $99(49)$ & 0.462 \\
Age, years (SD) & $7.6(0.4)$ & $7.6(0.4)$ & 0.399 \\
$\begin{array}{l}\text { Parental education, } \mathrm{n}(\%) \\
\text { Vocational school or less }\end{array}$ & $57(19)$ & $43(21)$ & 0.564 \\
$\quad$ Polytechnic & $139(46)$ & $85(43)$ & $72(36)$ \\
$\quad 107(35)$ & & 0.019 \\
$\quad$ University & & $55(28)$ \\
$\quad$ Household income, $\mathrm{n}(\%)$ & $51(17)$ & $76(39)$ \\
$\quad 132(43)$ & $65(33)$ \\
\hline $30,001-60,000 €$ & $117(38)$ &
\end{tabular}


Table 3 Imputed and adjusted physical activity values in the intervention group and in the control group

\begin{tabular}{|c|c|c|}
\hline & $\begin{array}{l}\text { Average of physical activity hours per child over two } \\
\text { years }\end{array}$ & $\begin{array}{l}\text { Values used in economic analysis }{ }^{\mathrm{a}} \text { (95 confidence } \\
\text { intervals) }\end{array}$ \\
\hline \multicolumn{3}{|l|}{ Intervention group } \\
\hline Baseline & $1369 \mathrm{~h}^{\mathrm{b}}$ & \\
\hline 2-year follow-up & $1477 h^{c}$ & \\
\hline Change over 2 years & $108.2 \mathrm{~h}$ & $54.0 \mathrm{~h}$ (47.6 to $60.5 \mathrm{~h})$ \\
\hline \multicolumn{3}{|l|}{ Control group } \\
\hline Baseline & $1306 \mathrm{~h}^{\mathrm{d}}$ & \\
\hline 2-year follow-up & $1241 h^{e}$ & \\
\hline Change over 2 years & -65.5 & -32.8 h (-40.9 to -24.2 h) \\
\hline $\begin{array}{l}\text { Incremental } \\
\text { effectiveness }\end{array}$ & $173.7 h^{f}$ & 86.8 h (76.1 to 97.0 h) \\
\hline
\end{tabular}

a Linear change in PA assumed, the trapezoidal rule applied, and change in PA divided by 2

${ }^{\mathrm{b}} 13.16 \mathrm{~h} / \mathrm{w} * 104$ weeks $=1368.64$ hours,

${ }^{c} 14.2 \mathrm{~h} / \mathrm{w} * 104$ weeks=1476.80 hours,

${ }^{d} 12.56 \mathrm{~h} / \mathrm{w} * 104$ weeks $=1306.24$ hours,

${ }^{\mathrm{e}} 11.93 \mathrm{~h} / \mathrm{w} * 104$ weeks=1240.72 hours,

${ }^{f} 108.16-(-65.52)=173.68$ hours

without parents' time use costs and $€ 860$ with these costs over two years. The net monetary benefit of the PA intervention, indicated by the point where the curve intersects the $\mathrm{x}$-axis in Fig. 1, is positive when willingness to pay for a 1-hour increase in PA is at least $€ 8.62$ with parents' time use costs (Fig. 1). Without these costs, the net monetary benefit of the PA intervention turns positive when the willingness to pay for a 1-hour increase in PA is at least $€ 6.21$ (Additional file 2). The willingness to pay required for $95 \%$ probability of cost- effectiveness was $€ 14$ without parents' time use costs and $€ 19$ with these costs (Fig. 2).

The cost per a 1-hour increase in PA varied between $€ 4.41$ and $€ 12.42$ in the sensitivity analyses (Additional file 3). The effectiveness of the PA intervention had the largest impact on incremental cost-effectiveness ratios. If we assumed that PA increased immediately after the initiation of the PA intervention, the net monetary benefit turns positive at $€ 4$.31.The results remained similar when using the intention-to-treat principle and when

Table 4 Resources used for the physical activity intervention and associated costs over two years

\begin{tabular}{|c|c|c|c|c|}
\hline & Resources used & Unit cost & Cost per exercise club & Cost per child \\
\hline \multicolumn{5}{|l|}{ Family-based physical activity counselling (6 visits) } \\
\hline Personnel costs of family-based counselling ${ }^{a}$ & $3.67 \mathrm{~h}$ & $€ 29.56$ & & $€ 108.50$ \\
\hline Printing costs of fact sheets given for the families & 20 pcs & $€ 0.08$ & & $€ 1.52$ \\
\hline Minor gifts for the families & & & & $€ 20.60$ \\
\hline Healthy snacks served to the children & & & & $€ 2.70$ \\
\hline Parents' time use costs ${ }^{b}$ & $8.67 \mathrm{~h}$ & $€ 27.78$ & & $€ 240.88$ \\
\hline \multicolumn{5}{|l|}{ After-school exercise clubs } \\
\hline Personnel costs of after-school exercise clubs ${ }^{c}$ & $76.00 h^{d}$ & $€ 58.49$ & $€ 4445.50^{\mathrm{e}}$ & $€ 348.67^{f}$ \\
\hline Costs of sports halls & $76.00 \mathrm{~h}^{\mathrm{d}}$ & $€ 23.05$ & $€ 1751.80^{\mathrm{g}}$ & $€ 137.40^{\mathrm{h}}$ \\
\hline All costs per child without parents' time use & & & & $€ 619.00$ \\
\hline All costs per child with parents' time use & & & & $€ 860.27$ \\
\hline
\end{tabular}

a) Personnel costs: exercise medicine specialist with average hourly wage $21.12 €+40 \%$ overhead $=€ 29.56 / \mathrm{h}$

b) Parents' time use costs. Average hourly wage in year $2014=€ 19.84+40 \%$ overhead $=€ 27.78 / \mathrm{h}$

c) 2 exercise instructors * 1.5 hours* $(€ 13.93+40 \%$ overhead $)=2 * 1.5$ hours $* € 19.50=€ 58.49$ per exercise club session

d) There were 38 exercise clubs per year and thus 76 exercise clubs during the 2 -year intervention.

e) Personnel costs for after-school exercise clubs ( $€ 58.49 * 76$ times) $=€ 4445.50$ per group

f) $(24$ groups * $€ 4445,50) / 306$ children $=€ 106692 / 306$ children $=€ 348.67$ per child

g) Costs of sports hall $(€ 23.05 * 76$ times $)=€ 1751.80$ per group

h) $(24$ groups * $€ 1751.80) / 306$ children $=€ 42043.20 / 306$ children $=€ 137.40$ per child 


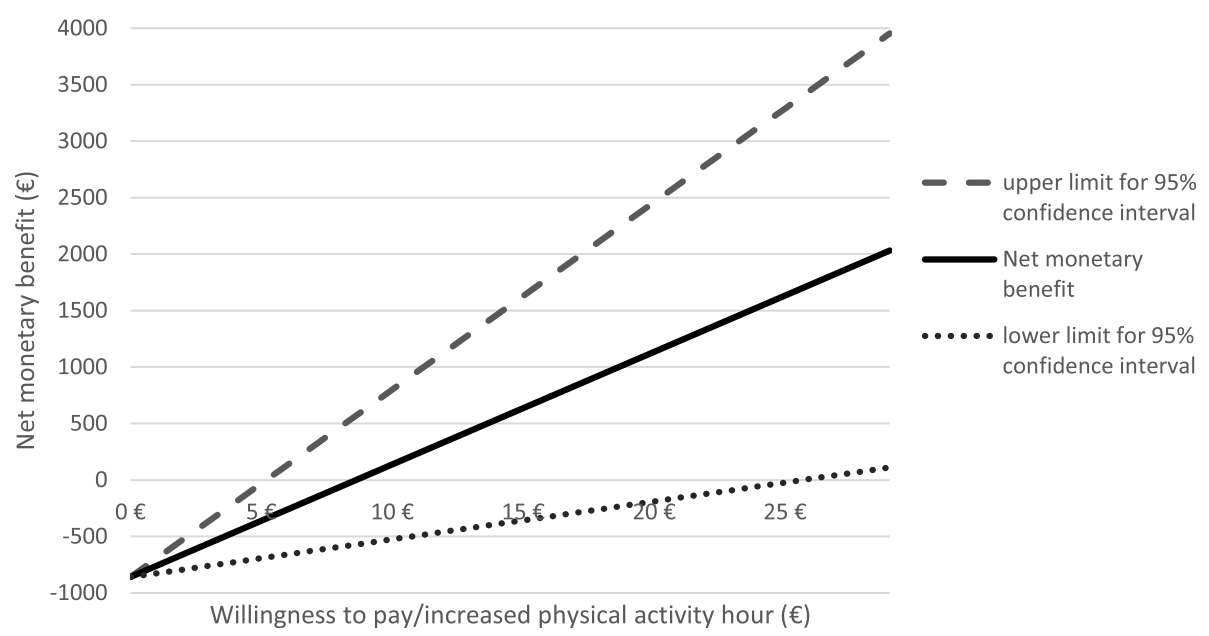

Fig. 1 Net monetary benefit with parents' time use costs in relation to willingness to pay for 1-hour increase in PA)

including only children with complete data, as indicated by the overlapping lines (Additional file 3). The incremental cost-effectiveness ratios were $€ 2-3$ lower without costs related to parents' time use.

\section{Discussion}

We assessed the cost-effectiveness of the 2-year PA intervention compared to no intervention in a general population of primary-school children aged 6-9 years. The PA intervention included six family-based and tailored PA counselling visits for all families in the intervention group and after-school exercise clubs, particularly for children in the intervention group who did not attend organised sports or exercise. The costeffectiveness analysis was performed from an extended service payer's perspective, with and without parents' time costs, by using imputed and adjusted PA values. PA was estimated to increase average by $54 \mathrm{~h}$ per child in the intervention group and to decrease average by $33 \mathrm{~h}$ per child in the control group over two years, the difference in PA change being $87 \mathrm{~h}$ over two years between the groups. The costs of the PA intervention over two years were $€ 619$ per child without parents' time costs and $€ 860$ per child with these costs. The PA intervention is cost-effective compared to no intervention among children if the service payer's willingness-to-pay for a 1hour increase in PA was $€ 6.21$ without parents' time costs and $€ 8.62$ with these costs.

The cost of increased PA hour was estimated by the incremental cost-effectiveness ratio (ICER) and was based on the net monetary benefit regression analyses assuming a linear change in PA. Our results mean that if

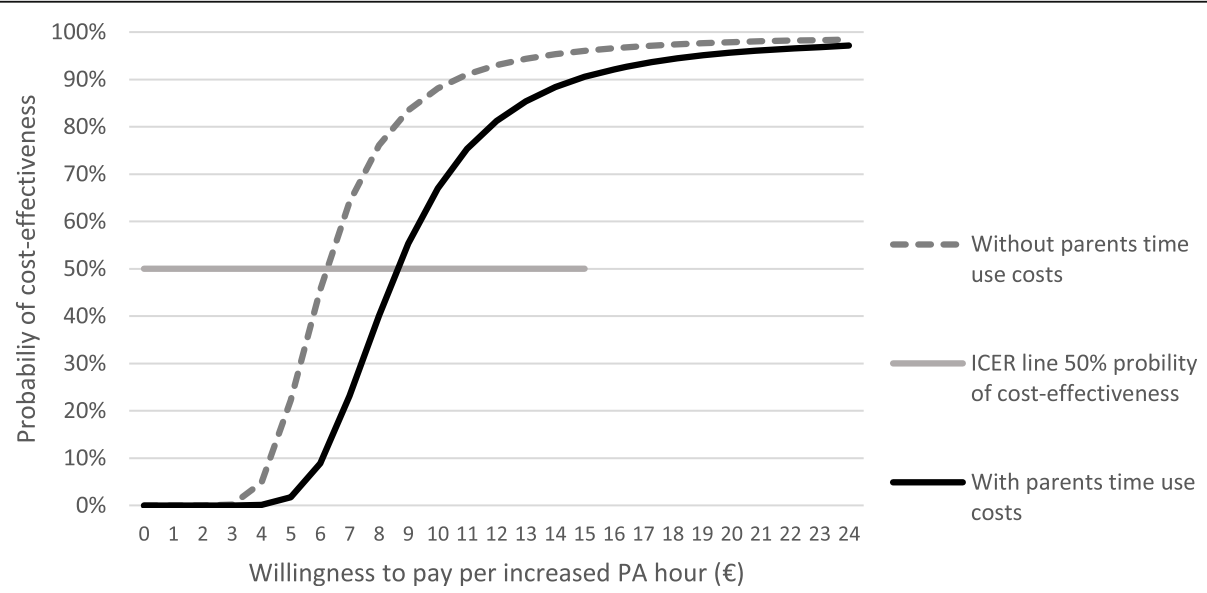

Fig. 2 Cost-effectiveness acceptability curves for 1-hour increase of PA showing the probability that the intervention is cost-effective compared to the control 
the service payers are satisfied with a $50 \%$ probability that the PA intervention is cost-effective compared with no intervention, the willingness to pay needs to be $€ 6.21$ per increased PA hour without parents' time costs and $€ 8.62$ with them. If they want to have at least $95 \%$ probability that the PA intervention is cost-effective, their willingness to pay needs to be $€ 14$ without parents' time costs and $€ 19$ with these costs. There is no generally accepted willingness-to-pay value for an hour increase in PA for children, so it makes sense to compare the costs of our PA intervention with those of other activities offered by the service payers, such as municipalities and parents. Swimming halls in Finland are mainly operated and subsidised by municipalities, and the cost of using swimming halls is estimated to be about $€ 6$ per visit [49, 50]. The swimming hall ticket costs $€ 4$ for a child and $€ 6.50$ for an adult, resulting in a total cost of $€ 10.50$ per visit. The costs of health-promotion services in the private sector tend to be more expensive than those provided by municipalities. The sensitivity analyses revealed that the cost of an increased PA hour without assuming a linear change (halving PA hours) in PA would be $€ 3.10$ without parents' time costs and $€ 4.31$ with these costs. In other words, halving intervention effectiveness increased the cost per PA hour gained. Moreover, the rental costs of sport halls vary widely in Finland, and higher costs would markedly increase the costs of the increased PA hour.

There is some evidence supporting the costeffectiveness of PA interventions combining the involvement of school and parents and targeting children [14, $17,21,22]$. For example, a new playscape installation in the metropolitan parks of Melbourne, Australia, resulted in increased PA and was observed to be cost-effective [14]. Among children, there was a net increase of 68884 metabolic equivalent (MET) hours over 14 months in the intervention group compared to the control group, together with other age groups, this intervention yield costs of 0.58 AUD\$ per MET-hour gained per visitor. Another Australian school-based PA intervention targeting adolescents was also found to be cost-effective with an ICER as high as 56 AUD\$ per an additional minute of moderate-to-vigorous PA gained per day [15]. The results of our study are not directly comparable to these findings because we had a family-based PA intervention for all families combined with after-school exercise clubs, particularly for children in the intervention group who did not attend organised sports or exercise, in a general population of Finnish children, and we used total PA hours as the outcome measure in our costeffectiveness analyses. We did not have the information about the intensity of $\mathrm{PA}$, so the use of metabolic equivalent [51] units and their thresholds for costeffectiveness [17] was not possible. One option would be to compare the cost-effectiveness ratios of different PA interventions by using the Relative Value Index [52]. However, there is no previous evidence on the costeffectiveness of PA interventions in general populations of children aged 6-9 years like in the PANIC study.

Because the focus in this paper was the costeffectiveness, the PA was assessed as whole. The art and type of PA have been explored in other PANIC articles [25]. Total PA at baseline was, on average, $1.9 \mathrm{~h}$ per day in our sample of children aged 6-9 years. When the PANIC study started in 2007, children of this age in Finland were recommended to have at least two hours of PA per day according to the national PA [53]. This recommendation was met by $40 \%$ of the children in the intervention group and by $39 \%$ of the children in the control group at baseline. At the 2-year follow-up, these proportions were 67 and $46 \%$ in favour of the intervention group. According to a recent review, children's PA decreases during the first school years [54], and the number of drop-outs in intervention studies among children with a lower socio-economic status is quite common [55]. Consistent with this finding, there were more drop-outs among families with lower education and household income in both groups. We do not have data on families that did not participate in our study, so we do not know whether socio-economic status affected the decision to attend. Parents usually make the decision whether to participate and continue in lifestyle interventions, particularly those including family-based lifestyle counselling. It may have been more difficult for parents with a lower education and household income to organise participation in the PA counselling visits because of their type of work, for example in a factory or a shop, than for parents with a higher socioeconomic status. Consistent with this assumption, children from families with lowest household income and education group were less likely to attend the PA counselling visits than those from higher-income and education families. The another explanation for these differences could be that individuals with a higher socioeconomic status (SES) are more health conscious and thus more likely to participate in health-related studies, such as the PANIC study, and also continue until the end of such studies than those with a lower SES [56]. We assumed that the parents needed to be absent from work due to the PA counselling visits, so their time costs were based on lost production. This assumption may cause overestimation of time costs because some parents may have shift work or may be unemployed, which could lower their costs of time. On the other hand, it may also result in underestimation of time costs if the parents were supposed to be asleep instead of working on a night shift or attending a job interview. 
The costs of the family-based PA counselling visits were $€ 133$ ( $15 \%$ of all costs), the parents' time use costs were $€ 241$ ( $28 \%$ ), and the costs of the after-school exercise clubs were $€ 486$ (57\%). Although the after-school exercise clubs represented only about $20 \%$ of the increased PA in the intervention group, they were the most expensive part of the PA intervention. This means that the family-based PA counselling visits rather than the after-school exercise clubs were cost-effective in our PA intervention. On the other hand, after-school exercise clubs are widely organised in Finland. The school halls in Finland are often available for after-school exercise clubs, especially in the early afternoon hours. In general, cooperation with schools should be part of the public health promotion strategy. In addition, most primary-school children aged 6-9 years need afterschool care and many municipalities also organise afternoon care that is partly subsidized by the state. In most municipalities, parents are responsible for the afternoon care expenses, the monthly fee being $€ 120-160$ [57] for 4-5 h per day. Our findings suggest that the familybased PA counselling visits contributed more to the increased PA but were less expensive to organise than the after-school exercise clubs. Although it is more challenging to implement than the after-school exercise clubs, the family-based PA counselling, possibly combined with dietary counselling, could be tested and implemented in the school health care of Finland. Before starting such health promotion activities, school nurses should be trained in lifestyle counselling. Nevertheless, extensive co-operation and planning among scientists and public health promoters is needed to implement the lifestyle counselling as part of the established activities of municipalities.

The strengths of our study include the populationbased sample of children studied and carrying out the PA intervention in a real-life setting. The careful economic evaluation of the data with a small number of drop-outs increased the reliability of the results. Moreover, the results using imputed and adjusted data and data on children who completed the 2-year intervention study were similar. The resources used for the PA intervention were well documented. We also used salaries and overheads based on national statistics that improved the reliability, generalisability, and transferability of the results. Another strength of our study is that the net monetary benefit regression approach was used. Especially with no official threshold for society's or service provider's willingness to pay, such as for a 1-hour increase in PA, this way of presenting the results is useful for decision makers and service payers. However, it would be easier to interpret the results if there was an agreement on the maximum willingness to pay for a 1hour increase in PA.
This study also has some limitations. Firstly, PA was assessed only twice, at baseline and at the 2-year followup, whereas the costs of the PA intervention accumulated throughout the two years. For the economic evaluation purpose, the weekly PA hours at baseline and at the 2-year follow-up were spread over the 2-year period to be comparable to the costs of the PA intervention over two years. This required an estimate of the change in PA when it occurred. We wanted to avoid overly optimistic conclusions and thus halved the change in PA by applying the trapezoidal rule and spread the weekly PA hours for two years. However, this analysis approach had a major impact on the results by decreasing the effectiveness of the PA intervention and raised the incremental cost-effectiveness ratio per a 1-hour increase in PA. It would be important for researchers to discuss how to make the effectiveness and costs of the interventions comparable in economic analyses if there are only two measurements of PA, but the costs are spread unequally over the study period. Finally, we assessed PA using a questionnaire filled out by the parents in our general population of children instead of objective measures, such as accelerometers or combined heart rate and body movement monitors. The reason for choosing a questionnaire to assess PA in the present analyses is that we wanted to assess changes in the time spent in PA behaviour rather than changes in energy expenditure or PA intensity, for which objective measures would have been a better choice.

\section{Conclusions}

Our study showed that the 2-year PA intervention combining family-based and tailored PA counselling and after-school exercise clubs was cost-effective in a general population of primary-school children. These findings provide further evidence that multicomponent PA interventions may be cost-effective in increasing PA among children. Our results suggest that the family-based PA counselling visits was a more cost-effective modality of the PA intervention than the after-school exercise clubs. It would therefore be important to test the effectiveness and cost-effectiveness of family-based PA counselling among children in health care. Our study also provides further evidence that it is more challenging to engage children from a lower socioeconomic background in long-term lifestyle intervention studies. The findings of our study are potentially important for the decision makers and service payers of health care when planning and implementing activities aimed at health promotion among children.

\section{Supplementary Information}

The online version contains supplementary material available at https://doi. org/10.1186/s12966-021-01181-0. 


\section{Additional file $1:$ \\ Additional file 2 : \\ Additional file 3:}

\section{Acknowledgements}

We are grateful to all the children and their parents for participating in the PANIC study. We are also indebted to the members of the PANIC research team for their contribution in performing the study.

\section{Authors' contributions}

VKK, NL, VL, HV, and TAL designed the study. VKK, NL, VL, A-ME, and SK conducted the study. ER, JM, EK, HV, and TAL provided scientific advice for conduction of the study. VKK, NL, ER, JM, EK, HV, and TAL planned and performed the statistical analyses and interpreted the results. VKK drafted the manuscript and is the principal investigator of this paper. All authors critically revised the manuscript for its intellectual content and approved the final version of the manuscript.

\section{Funding}

The PANIC Study has financially been supported by grants from the Ministry of Education and Culture of Finland, the Ministry of Social Affairs and Health of Finland, the Research Committee of the Kuopio University Hospital Catchment Area (State Research Funding), the Finnish Innovation Fund Sitra, the Social Insurance Institution of Finland, the Finnish Cultural Foundation, the Foundation for Paediatric Research, the Diabetes Research Foundation in Finland, the Finnish Foundation for Cardiovascular Research, the Juho Vainio Foundation, the Paavo Nurmi Foundation, the Yrjö Jahnsson Foundation, and the city of Kuopio. These sources of funding had no role in the design of the study, collection, analyses and interpretation of the data or involvement in writing the manuscript.

\section{Availability of data and materials}

Data availability Information about the PANIC study and the data used in the present paper are available at www.panicstudy.fi/en/etusivu. The data are not publicly available due to research ethical reasons and because the owner of the data is the University of Eastern Finland and not the research group. However, the corresponding author can provide further information on the PANIC study and the PANIC data on a reasonable request.

\section{Declarations}

\section{Ethical approval and consent to participate}

This study is registered at www.clinicaltrials.gov (No. NCT01803776). The Research Ethics Committee of the Hospital District of Northern Savo approved the study protocol in 2006 (Statement 69/2006). The parents or caregivers of the children gave their written informed consent, and the children provided their assent to participation. The PANIC study has been carried out in accordance with the principles of the Declaration of Helsinki as revised in 2008 .

\section{Consent for publication}

Not applicable.

\section{Competing interests}

J.M. is a partner of ESiOR Oy, which provides health economic, outcome research, and market access services for pharmaceutical, medical device companies, and hospitals. Other authors declare that they have no competing interests.

\section{Author details}

${ }^{1}$ Department of Health and Social Management, University of Eastern Finland, Kuopio, Finland. ${ }^{2}$ Institute of Biomedicine, School of Medicine, University of Eastern Finland, Kuopio, Finland. ${ }^{3}$ Library, University of Eastern Finland, Kuopio, Finland. ${ }^{4}$ Institute of Public Health and Clinical Nutrition, School of Medicine, University of Eastern Finland, Kuopio, Finland. ${ }^{5}$ School of Pharmacy, University of Eastern Finland, Kuopio, Finland. ${ }^{6}$ Kuopio Research Institute of Exercise Medicine, Kuopio, Finland. ${ }^{7}$ Department of Clinical
Physiology and Nuclear Medicine, Kuopio University Hospital, Kuopio, Finland.

Received: 5 May 2021 Accepted: 2 August 2021

Published online: 06 September 2021

\section{References}

1. Katzmarzyk PT, Janssen I. The economic costs associated with physical inactivity and obesity in Canada: an update. Canadian journal of applied physiology. 2004;29(1):90-115.

2. Lee IM, Shiroma EJ, Lobelo F, Puska P, Blair SN, Katzmarzyk PT, et al. Effect of physical inactivity on major non-communicable diseases worldwide: an analysis of burden of disease and life expectancy. Lancet. 2012;380(9838): 219-29.

3. Hirvensalo M, Lintunen T. Life-course perspective for physical activity and sports participation. European Review of Aging Physical Activity. 2011;8(1): 13.

4. Kremers SP, Brug J. Habit strength of physical activity and sedentary behavior among children and adolescents. Pediatr Exerc Sci. 2008;20(1):517.

5. Telama R, Yang X, Viikari J, Valimaki I, Wanne O, Raitakari O. Physical activity from childhood to adulthood: a 21-year tracking study. Am J Prev Med. 2005;28(3):267-73.

6. Aarts $\mathrm{H}$, Paulussen T, Schaalma H. Physical exercise habit: on the conceptualization and formation of habitual health behaviours. Health Education Research. 1997:12(3):363-74.

7. Chen L, Magliano DJ, Zimmet PZ. The worldwide epidemiology of type 2 diabetes mellitus-present and future perspectives. Nat Rev Endocrinol. 2011; 8(4):228-36.

8. Messing S, Rutten A, Abu-Omar K, Ungerer-Rohrich U, Goodwin L, Burlacu I, et al. How Can Physical Activity Be Promoted Among Children and Adolescents? A Systematic Review of Reviews Across Settings. Front Public Health. 2019;7:55

9. van Sluijs EM, McMinn AM, Griffin SJ. Effectiveness of interventions to promote physical activity in children and adolescents: systematic review of controlled trials. BMJ. 2007;335(7622):703.

10. Brown HE, Atkin AJ, Panter J, Wong G, Chinapaw MJ, Van Sluijs E. Familybased interventions to increase physical activity in children: a systematic review, meta-analysis and realist synthesis. Obesity reviews. 2016;17(4):34560.

11. Harris C, Allen K, Waller C, Brooke V. Sustainability in health care by allocating resources effectively (SHARE) 3: examining how resource allocation decisions are made, implemented and evaluated in a local healthcare setting. BMC Health Serv Res. 2017;17(1):340.

12. Drummond MF, Sculpher MJ, Claxton K, Stoddart GL, Torrance GW. Methods for the economic evaluation of health care programmes. Oxford university press; 2015.

13. Goodacre S, McCabe C. An introduction to economic evaluation. Emerg Med J. 2002;19(3):198-201.

14. Lal A, Moodie M, Abbott G, Carver A, Salmon J, Giles-Corti B, et al. The impact of a park refurbishment in a low socioeconomic area on physical activity: a cost-effectiveness study. Int J Behav Nutr Phys Act. 2019;16(1):1-8.

15. Sutherland R, Reeves P, Campbell E, Lubans DR, Morgan PJ, Nathan N, et al. Cost effectiveness of a multi-component school-based physical activity intervention targeting adolescents: the 'Physical Activity 4 Everyone' cluster randomized trial. Int J Behav Nutr Phys Act. 2016;13:94

16. Callahan LF, Rao J, Boutaugh M. Arthritis and women's health: prevalence, impact, and prevention. Am J Prev Med. 1996;12(5):401-9.

17. Wu S, Cohen D, Shi Y, Pearson M, Sturm R. Economic analysis of physical activity interventions. Am J Prev Med. 2011;40(2):149-58.

18. John J, Wolfenstetter SB, Wenig CM. An economic perspective on childhood obesity: recent findings on cost of illness and cost effectiveness of interventions. Nutrition. 2012:28(9):829-39.

19. McAuley KA, Taylor RW, Farmer VL, Hansen P, Williams SM, Booker CS, et al. Economic evaluation of a community-based obesity prevention program in children: The APPLE project. Obesity. 2010;18(1):131-6.

20. Vijay SG, Suhrcke M, Atkin AJ, van Sluijs E, Turner D. Cost-effectiveness of physical activity interventions in adolescents: model development and illustration using two exemplar interventions. BMJ Open. 2019;9(8):e027566.

21. Cradock AL, Barrett JL, Kenney EL, Giles CM, Ward ZJ, Long MW, et al. Using cost-effectiveness analysis to prioritize policy and programmatic approaches 
to physical activity promotion and obesity prevention in childhood. Prev Med. 2017:95:S17-27.

22. Barrett JL, Gortmaker SL, Long MW, Ward ZJ, Resch SC, Moodie ML, et al. Cost Effectiveness of an Elementary School Active Physical Education Policy. Am J Prev Med. 2015;49(1):148-59.

23. Abu-Omar K, Rutten A, Burlacu I, Schatzlein V, Messing S, Suhrcke M. The cost-effectiveness of physical activity interventions: A systematic review of reviews. Prev Med Rep. 2017;8:72-8.

24. Venalainen TM, Viitasalo AM, Schwab US, Eloranta AM, Haapala EA, Jalkanen $\mathrm{HP}$, et al. Effect of a 2-y dietary and physical activity intervention on plasma fatty acid composition and estimated desaturase and elongase activities in children: the Physical Activity and Nutrition in Children Study. Am J Clin Nutr. 2016;104(4):964-72

25. Viitasalo A, Eloranta AM, Lintu N, Vaisto J, Venalainen T, Kiiskinen S, et al. The effects of a 2-year individualized and family-based lifestyle intervention on physical activity, sedentary behavior and diet in children. Prev Med. 2016;87: 81-8.

26. Lakka TA, Lintu N, Vaisto J, Viitasalo A, Sallinen T, Haapala EA, et al. A 2 year physical activity and dietary intervention attenuates the increase in insulin resistance in a general population of children: the PANIC study. Diabetologia. 2020:63(11):2270-81.

27. Haapala EA, Poikkeus AM, Kukkonen-Harjula K, Tompuri T, Lintu N, Vaisto J, et al. Associations of physical activity and sedentary behavior with academic skills-a follow-up study among primary school children. PLoS One. 2014; 9(9):e107031.

28. Vaisto J, Eloranta AM, Viitasalo A, Tompuri T, Lintu N, Karjalainen P, et al. Physical activity and sedentary behaviour in relation to cardiometabolic risk in children: cross-sectional findings from the Physical Activity and Nutrition in Children (PANIC) Study. Int J Behav Nutr Phys Act. 2014;11(1):1-10

29. Lintu N. Publications of the University of Eastern Finland Dissertations in Health Sciences Number 395. University of Eastern Finland; Kuopio, 2017. https://erepo.uef.fi/bitstream/handle/123456789/17600/urn_isbn_978-95261-2398-1.pdf? sequence=1\&isAllowed=y.

30. Salary Guide Health Sciences (in Finnish). 2012. https://docplayer.fi/3564475Palkkaopas-versio-8-10-2012-terveystieteiden-johtajat-ja-asiantuntijat-ry.html.

31. Official Statistics of Finland (OSF): Labour cost survey [e-publication]. ISSN = 1799-3288. 2012, Appendix Table 2. Structure of labour costs by sector in 2012. Helsinki: Statistics Finland [Internet]. [cited 15.10.2016]. Available from: http://www.stat.fi/til/tvtutk/2012/tvtutk_2012_2014-09-26_tau_002_en.html.

32. Krol M, Brouwer W. How to estimate productivity costs in economic evaluations. Pharmacoeconomics. 2014;32(4):335-44.

33. Official Statistics of Finland (OSF); Wages, Salaries and Labour costs [Internet]. Official Statistics of Finland (OSF); Wages, Salaries and Labour costs [cited 20.10.2017]. Available from: https://www.stat.fi/til/pra/2014/ pra_2014_2015-10-14_tie_001_en.html.

34. College Station TX. StataCorp LLC. StataCorp. 2017. Stata Statistical Software: Release 15. College Station. TX: StataCorp LLC; 2017:15.1.

35. Ramsey S, Willke R, Briggs A, Brown R, Buxton M, Chawla A, et al. Good Research Practices for Cost-Effectiveness Analysis Alongside Clinical Trials: The ISPOR RCT-CEA Task Force Report. Value in Health. 2005;8(5):521-33.

36. Ramsey SD, Willke RJ, Glick H, Reed SD, Augustovski F, Jonsson B, et a Cost-effectiveness analysis alongside clinical trials II-An ISPOR Good Research Practices Task Force report. Value Health. 2015;18(2):161-72.

37. Gabrio A, Mason AJ, Baio G. Handling missing data in within-trial costeffectiveness analysis: a review with future recommendations. PharmacoEconomics-Open. 2017;1(2):79-97.

38. Faria R, Gomes M, Epstein D, White IR. A guide to handling missing data in cost-effectiveness analysis conducted within randomised controlled trials. Pharmacoeconomics. 2014;32(12):1157-70.

39. White IR, Royston P, Wood AM. Multiple imputation using chained equations: Issues and guidance for practice. Stat Med. 2011;30(4):377-99.

40. Byberg L, Melhus H, Gedeborg R, Sundstrom J, Ahlbom A, Zethelius B, et al. Total mortality after changes in leisure time physical activity in 50 year old men: 35 year follow-up of population based cohort. Br J Sports Med. 2009; 338:b688.

41. Martikainen S, Pesonen AK, Lahti J, Heinonen K, Feldt K, Pyhala R, et al. Higher levels of physical activity are associated with lower hypothalamicpituitary-adrenocortical axis reactivity to psychosocial stress in children. J Clin Endocrinol Metab. 2013;98(4):E619-27

42. Hoch JS, Rockx MA, Krahn AD. Using the net benefit regression framework to construct cost-effectiveness acceptability curves: an example using data from a trial of external loop recorders versus Holter monitoring for ambulatory monitoring of "community acquired" syncope. BMC Health Serv Res. 2006;6:68

43. Hoch JS, Dewa CS. Lessons from Trial-Based Cost-Effectiveness Analyses of Mental Health Interventions. Pharmacoeconomics. 2007;25(10):807-16.

44. Kesztyus D, Schreiber A, Wirt T, Wiedom M, Dreyhaupt J, Brandstetter S, et al. Economic evaluation of URMEL-ICE, a school-based overweight prevention programme comprising metabolism, exercise and lifestyle intervention in children. Eur J Health Econ. 2013;14(2):185-95.

45. Hoch JS, Briggs AH, Willan AR. Something old, something new, something borrowed, something blue: a framework for the marriage of health econometrics and cost-effectiveness analysis. Health Econ. 2002;11(5):41530.

46. Hoch JS, Dewa CS. Advantages of the net benefit regression framework for economic evaluations of interventions in the workplace: a case study of the cost-effectiveness of a collaborative mental health care program for people receiving short-term disability benefits for psychiatric disorders. J Occup Environ Med. 2014;56(4):441-5.

47. Glick HA, Doshi JA, Sonnad SS, Polsky D. Economic evaluation in clinical trials. Second edition ed. OUP Oxford; 2015.

48. Fimean suositus lääkkeiden hoidollisen ja taloudellisen arvon arvioinnista (in Finnish). Fimean julkaisusarja 2/2012.

49. Nissinen K. Tilateho-hankkeen loppuraportti N:01 (in Finnish). Teknologian tutkimuskeskus VTT 2006. http://www.vtt.fi/inf/julkaisut/muut/2006/Kunna tloppuraportti17022006.pdf.

50. Laakso T. Production models of swimming hall services in public sector (in Finnish). Faculty of Sport and Health Sciences, University of Jyväskylä, Master's thesis in Social Sciences of Sport 2017. https://jyx.jyu.fi/bitstream/ha ndle/123456789/55622/1/URN\%3ANBN\%3Afi\%3Ajyu-201710133988.pdf.

51. Ainsworth B, Haskell W, Whitt M, Irwin ML, Swartz AM, Strath SJ, et al. Compendium of physical activities: an update of activity codes and MET intensities. Med Sci Sports Exerc. 2000;32(9 Suppl):498-504.

52. Hyewon $\mathrm{HL}$, Levine $\mathrm{M}$. Determining the threshold for acceptability of an ICER when natural health units are used. Journal of Population Therapeutics and Clinical Pharmacology. 2012:19(2):e234-8.

53. Recommendations for physical activity in early childhood education (in Finnish). Handbooks of the Ministry of Social Affairs and Health, Helsinki 2005 ISSN 1236-116X; 2005:17. https://julkaisut.valtioneuvosto.fi/bitstream/ha ndle/10024/72925/URN\%3ANBN\%3Afi-fe201504225286.pdf? sequence=1.

54. Lounassalo I, Salin K, Kankaanpää A, Hirvensalo M, Palomäki S, Tolvanen A, et al. Distinct trajectories of physical activity and related factors during the life course in the general population: a systematic review. BMC Public Health. 2019;19(1):1-12.

55. De Coen V, De Bourdeaudhuij I, Vereecken C, Verbestel V, Haerens L, Huybrechts I, et al. Effects of a 2-year healthy eating and physical activity intervention for 3-6-year-olds in communities of high and low socioeconomic status: the POP (Prevention of Overweight among Pre-school and school children) project. Public Health Nutr. 2012:15(9):1737-45.

56. Ligthart KA, Buitendijk L, Koes BW, van Middelkoop M. The association between ethnicity, socioeconomic status and compliance to pediatric weight-management interventions-a systematic review. Obesity research clinical practice. 2017;11(5):1-51.

57. Morning and afternoon activities. Ministry of Education and Culture. Finland. https://minedu.fi/en/before-and-after-school-activities.

\section{Publisher's Note}

Springer Nature remains neutral with regard to jurisdictional claims in published maps and institutional affiliations. 